more frequently, and textbooks less frequently, than their more junior counterparts. In addition to the reasons the authors put forward, I would also suggest that the differing information-accessing habits of senior and junior trainees can be explained by the distinction made in the evidence-based medicine literature between 'background' and 'foreground' knowledge. ${ }^{3}$

'Background' knowledge concerns well-established facts/general knowledge. The most suitable information sources for retrieving background knowledge are textbooks or electronic 'point of care' resources such as UpToDate (www.uptodate.com/home), Clinical Evidence (http:// clinicalevidence.bmj.com/x/index.html) or DynaMed (www.dynamed.com/home). It is primarily junior health professionals or students who require background knowledge, hence Walker-Tilley et al's finding that the junior psychiatrists made more use of textbooks than their more senior colleagues.

Senior clinicians' information needs typically relate to 'foreground' knowledge, which is usually needed to support a specific aspect of clinical decision-making. Textbooks are not a recommended source to answer 'foreground' questions because these questions require a synthesis of the latest research and there is no way to ascertain which information in textbooks is, or is not, current. ${ }^{3}$

It is plausible that advanced trainees are using textbooks less than more junior trainees ${ }^{2}$ because they are posing more 'foreground' questions (owing to the more advanced stage of their training). It is also likely that advanced trainees are posing more of these questions because they work with greater autonomy in their clinical practice than their more junior counterparts.

I did, however, find Walker-Tilley et al's categorisation of information sources somewhat confusing. In particular, the category of 'websites' seems imprecise because the term websites relates to a means of accessing and storing information (i.e. the internet) as well as covering a great many types of information source. The authors report that their psychiatry trainee respondents consulted websites via search engines more frequently than textbooks and journals. This accords with previous research which has found that clinicians commonly use internet search engines to access research. ${ }^{4}$ This finding is not, however, an end in itself because search engines signpost their users to many information sources but it is not clear which sources (or what kinds of websites) the clinicians then choose to consult. Also, while it is argued ${ }^{2}$ that Google may be a valuable tool to physicians in clarifying diagnosis, much of the information which Google finds is unfiltered, meaning that the burden of critical appraisal falls entirely on the clinician. ${ }^{3}$ Likewise, Wikipedia users must counterbalance the advantage of being able to find information quickly and easily with the disadvantage of this information being of variable quality. ${ }^{5}$
It would be very valuable if future research could probe in more detail which websites/online resources psychiatry trainees are accessing in their clinical practice since, as Walker-Tilley et al rightly point out, it is vital that trainees continue to possess the necessary skills to identify, access and appraise relevant information at the point of clinical need.

1 Giguère $A$, Légaré $F$, Grimshaw J, Turcotte $S$, Fiander $M$, Grudniewicz $A$ et al. Printed educational materials: effects on professional practice and healthcare outcomes. Cochrane Database Syst Rev 2012; 10: CD004398.

2 Walker-Tilley T, Bainton J, Fernando M, Wong Y, Ko B, Warner J, et al. How psychiatric trainees keep up to date: survey of psychiatric trainees' use of journals and other information sources. BJPsych Bull 2015; doi: 10.1192/pb.bp.113.045682.

3 Straus SE, Glasziou P, Richardson WS, Haynes RB. Evidence-Based Medicine: How to Practice and Teach EBM. Churchill Livingstone Elsevier, 2011.

4 Hider PN, Griffin G, Walker M, Coughlan E. The information-seeking behavior of clinical staff in a large health care organization. J Med Libr Assoc 2009; 97: 47-50.

5 Herbert VG, Frings A, Rehatschek H, Richard G, Leithner A Wikipedia - challenges and new horizons in enhancing medical education. BMC Med Educ 2015; 15: 32.

Rachel Steele, Clinical Librarian, Tees, Esk and Wear Valleys NHS Foundation Trust, email: rachelsteele@nhs.net

doi: 10.1192/pb.39.4.206a

\section{National Confidential Inquiry}

It has been drawn to my attention that my article implicitly criticises the National Confidential Inquiry into Suicide and Homicide by People with Mental Illness ( $\mathrm{NCl}$ ), attributing to it comments which are rarely if ever found in its pages. In fact the $\mathrm{NCl}$ makes specific focused recommendations which, when implemented, reduce suicide rates. ${ }^{2}$ My remarks, admittedly anecdotal, based on my own and colleagues' experiences, were directed not so much at the $\mathrm{NCl}$, but at internal hospital enquiries and the double standards which pervade the way psychiatric and non-psychiatric deaths are handled. I stand however by the view that administrative fragmentation, underfunding and de-professionalisation of psychiatry all play their part when people suffering from psychiatric illnesses kill themselves.

1 Holmes J. Personal experience: Suicide and psychiatric care - a lament BJPsych Bull 2015; 39: 45-7.

2 While D, Bickley H, Roscoe A, Windfuhr K, Rahman S, Shaw J, et al. Implementation of mental health recommendations in England and Wales and suicide rates, 1997-2006: a cross-sectional before-and-after observational study. Lancet 2012; 379: 1005-12.

Jeremy Holmes, Retired Consultant Psychiatrist, University of Exeter, email: j.a.holmes@btinternet.com

doi: $10.1192 / p b .39 .4 .207$

\title{
Bulletin
}

